\title{
Sublingual immunotherapy for peanut allergy: a randomized, double-blind, placebo-controlled multicenter trial
}

\author{
David M. Fleischer, MD ${ }^{1,{ }^{*}}$, A. Wesley Burks, MD2, ${ }^{*}$, Brian P. Vickery, MD ${ }^{2}$, Amy M. Scurlock, \\ MD $^{3}$, Robert A. Wood, MD ${ }^{4}$, Stacie M. Jones, MD ${ }^{3}$, Scott H. Sicherer, MD ${ }^{5}$, Andrew H. Liu, \\ MD $^{1}$, Donald Stablein, PhD $^{6}$, Alice K. Henning, MS $^{6}$, Lloyd Mayer, MD ${ }^{5}$, Robert Lindblad, \\ MD ${ }^{6}$, Marshall Plaut, MD ${ }^{7}$, and Hugh A. Sampson, MD $^{5}$ for the Consortium of Food Allergy \\ Research (CoFAR) \\ ${ }^{1}$ Department of Pediatrics, National Jewish Health, Denver, CO \\ 2Department of Pediatrics, University of North Carolina, Chapel Hill, NC \\ ${ }^{3}$ Department of Pediatrics, University of Arkansas for Medical Sciences and Arkansas Children's \\ Hospital, Little Rock, AR \\ ${ }^{4}$ Department of Pediatrics, Johns Hopkins University School of Medicine, Baltimore, MD \\ ${ }^{5}$ Department of Pediatrics, Mount Sinai School of Medicine, New York, NY \\ ${ }^{6}$ The EMMES Corporation, Rockville, MD \\ ${ }^{7}$ National Institutes of Health (NIAID), Bethesda, MD
}

\section{Abstract}

Background-There are presently no available therapeutic options for peanut-allergic patients.

Objective-To investigate the safety, efficacy, and immunologic effects of peanut sublingual immunotherapy (SLIT).

\begin{abstract}
Methods-After a baseline oral food challenge (OFC) of up to $2 \mathrm{~g}$ of peanut powder ( $\sim 50 \%$ protein) (median successfully consumed dose [SCD] 46mg), 40 subjects, aged 12-37 (median 15) years, were randomized 1:1 across 5 sites to daily peanut or placebo SLIT. A 5g OFC was performed after 44 weeks followed by unblinding; placebo subjects then crossed over to higher dose peanut SLIT, followed by a subsequent crossover Week 44 5g OFC. Week 44 OFCs from both groups were compared to baseline OFCs; subjects successfully consuming $5 \mathrm{~g}$ or at least 10fold more peanut powder than the baseline OFC threshold were considered responders.
\end{abstract}

Results-After 44 weeks of SLIT, 14/20 (70\%) subjects receiving peanut SLIT were responders compared to $3 / 20(15 \%)$ subjects receiving placebo $(\mathrm{p}<0.001)$. In peanut-SLIT responders, median SCD increased from $3.5 \mathrm{mg}$ to $496 \mathrm{mg}$. After 68 weeks of SLIT, median SCD significantly increased to $996 \mathrm{mg}$ (compared to week $44, \mathrm{p}=0.05$ ). The median SCD at the Week 44 crossover OFC was significantly higher than baseline (603mg vs $71 \mathrm{mg} ; \mathrm{p}=0.02) .7 / 16(44 \%)$ crossover subjects were responders; median SCD increased from $21 \mathrm{mg}$ to $496 \mathrm{mg}$ among responders. Of

(C) 2012 American Academy of Allergy, Asthma and Immunology. Published by Mosby, Inc. All rights reserved.

Corresponding Author: David M. Fleischer, MD, National Jewish Health, 1400 Jackson Street, J321, Denver, CO 80206. Fleischerd@njhealth.org; Tel: 303-398-1876; Fax: 303-270-2189.

Drs. Fleischer and Burks contributed equally to this manuscript.

Publisher's Disclaimer: This is a PDF file of an unedited manuscript that has been accepted for publication. As a service to our customers we are providing this early version of the manuscript. The manuscript will undergo copyediting, typesetting, and review of the resulting proof before it is published in its final citable form. Please note that during the production process errors may be discovered which could affect the content, and all legal disclaimers that apply to the journal pertain. 
10,855 peanut doses through Week 44 OFCs, $63.1 \%$ were symptom-free; excluding oral/ pharyngeal symptoms, $95.2 \%$ were symptom-free.

Conclusions-Peanut SLIT safely induced a modest level of desensitization in a majority of subjects compared to placebo. Longer duration of therapy showed statistically significant increases in the SCD.

\section{Keywords}

peanut allergy; sublingual immunotherapy; desensitization; food allergy

\section{INTRODUCTION}

Peanut allergy prevalence is increasing, with significant effects on health-related quality of life. ${ }^{(1)}$ Peanuts and tree nuts are the most common triggers of severe and fatal food-induced anaphylactic reactions, ${ }^{(2 ; 3)}$ and peanut allergy is less commonly outgrown than allergy to other major food allergens; thus significant, lifelong changes in dietary habits are required. Given the ever-present fear of severe allergic reactions from accidental ingestions and food product contamination, ${ }^{(4-6)}$ the potential for severe or fatal reactions, ${ }^{(3 ; 7)}$ the need for strict elimination diets and difficulty interpreting food labels, ${ }^{(8 ; 9)}$ a diagnosis of food allergy has significant medical, nutritional and psychosocial implications for affected individuals and families. ${ }^{(10-14)}$ Additionally, there is a substantial economic impact, as investigators have also reported increased health care expenditures associated with food allergy. ${ }^{(15-17)}$ Standard clinical care for peanut allergy currently includes strict dietary elimination and ready access to injectable epinephrine in case of accidental ingestions; there are presently no broadly available therapeutic options for food-allergic patients. Traditional subcutaneous immunotherapy has proven unsafe for peanut allergy, ${ }^{(18)}$ but novel immunomodulatory approaches such as oral immunotherapy (OIT) are under investigation and have shown promise as therapeutic options. ${ }^{(19 ; 20)}$ However, further study is warranted before these approaches become part of mainstream clinical care. ${ }^{(21)}$

Sublingual immunotherapy (SLIT) has demonstrated clinical efficacy in treatment of asthma and allergic rhinitis associated with a favorable safety profile. ${ }^{(22-24)}$ SLIT has also been utilized for treatment of allergy to several foods including kiwi, hazelnut, peach, milk and most recently peanut. ${ }^{(25-31)}$

In this study we examined the clinical effects and safety profile of peanut SLIT in what is to date the first multicenter, randomized, placebo-controlled trial. We present data on the primary end point of the study, the percentage of desensitized subjects, as well as several secondary end points including tolerability of up-dosing, differences in response between treatment dosing arms, safety profile, and immunologic outcomes.

\section{METHODS}

\section{Study design}

The first phase of the study was a randomized, double-blind, placebo-controlled peanut SLIT trial through 44 weeks. The second phase was an unblinded additional 120 weeks of lower dose peanut SLIT treatment for the initial active subjects, and 164 weeks of higher dose peanut SLIT for the placebo subjects following crossover to active therapy. For an illustration of the study protocol, see Figure E1 in the Online Repository at www.jacionline.org. The data presented in this manuscript include information through Week 68 for Peanut SLIT subjects and through Week 44 after initiation of crossover higher 
dose peanut SLIT therapy for Placebo Crossover subjects (which corresponds to 88 weeks after study entry and 44 weeks after the Week 44 Crossover OFC).

The primary end point was the percentage of desensitized subjects measured by the $5 \mathrm{~g}$ peanut powder ( $2.5 \mathrm{~g}$ peanut protein) oral food challenge (OFC) performed 44 weeks after initiation of therapy (Week 44 Unblinding OFC). Responders were defined as those who could consume, without dose-limiting symptoms, either a cumulative dose of $5 \mathrm{~g}$ or a 10 -fold increase in the amount of peanut powder compared to their baseline OFC. Key secondary end points included (1) the percentage of subjects tolerating the 16-36 week build-up stage, (2) immunologic end points, including immunologic changes in IgE, IgG4, skin prick test (SPT) and basophil activation, and (3) incidence of serious adverse events.

\section{Subject recruitment}

Forty subjects were recruited from 5 US sites (New York, NY, Baltimore, MD, Little Rock, AR, Denver, CO, Durham, NC; the North Carolina subjects moved with the investigative team from Duke to the University of North Carolina-Chapel Hill in March 2012). A cohort of subjects aged 18-40 years was enrolled initially; after 20 weeks of therapy and Data Safety Monitoring Board (DSMB) review, subjects aged 12 to 40 years were enrolled. The study was conducted with investigational new drug approval from the US Food and Drug Administration. A NIAID DSMB and local Institutional Review Boards approved study procedures, and written informed consents were obtained.

\section{Subject selection and randomization}

Inclusion criteria required a clinical history or physician diagnosis of peanut allergy, positive peanut SPT (wheal diameter $>3 \mathrm{~mm}$ after subtracting saline control) or detectable peanutspecific IgE (PN-IgE) ( $\searrow$. 35 kilounits of antibody per liter $\left[\mathrm{kU} \mathrm{A}_{\mathrm{A}} / \mathrm{L}\right]$ ), and a positive baseline double-blind, placebo-controlled food challenge (DBPCFC) to peanut (defined as objective allergic symptoms at a cumulative dose of $\_\mathrm{g}$ of peanut powder). Exclusion criteria included a history of severe anaphylaxis to peanut, defined as involving hypoxia, hypotension or neurologic compromise; asthma with FEV1<80\% predicted, or clinical features of moderate or severe persistent asthma and $>500 \mu \mathrm{g} / \mathrm{d}$ fluticasone or fluticasone equivalent; history of intubation; or other significant nonallergic medical conditions.

Qualifying subjects were randomized 1:1 to receive either peanut SLIT or placebo. Assignments were centrally prepared, stratified by site and sequentially provided to unblinded site pharmacists. Primary investigators, clinical and laboratory staff, subjects, and families remained blinded through Week 44 of the study's first phase.

\section{Study protocol}

Subjects were instructed to remain on a peanut-free diet throughout the entire study and required to carry an epinephrine autoinjector. Solicited dosing symptoms were recorded on a daily basis. Other unsolicited adverse events were separately recorded. All escalation dosing was observed in monitored research units equipped with emergency medications. Study drug was administered sublingually, held for 2 minutes, and then swallowed.

Escalation dosing-Dosing started at $0.000165 \mu \mathrm{g}$ of peanut protein (1 pump of a $1: 20,000,000 \mathrm{w} / \mathrm{v}$ dilution) or placebo (see the Methods section for study medication details and Table E1 in the Online Repository for full escalation dosing). Escalation through $660 \mu \mathrm{g}$ occurred every 2 weeks, with 3 doses attempted at a minimal interval of 30 minutes. If subjects failed 3-dose escalations after 3 consecutive biweekly attempts, one or two dose biweekly escalations were allowed subsequently. Subjects were monitored for 30 minutes after dosing (if no symptoms or only oral/pharyngeal symptoms occurred) or longer 
depending on symptoms. After each observed dose, subjects continued the same daily dose at home for 2 weeks. After the $660 \mu \mathrm{g}$ was achieved, single dose increases occurred followed by 2 weeks of maintenance therapy.

Maintenance dosing-During the first phase, subjects took a minimum dose of $165 \mu \mathrm{g}$ and a maximum maintenance dose of $1386 \mu \mathrm{g}$ of peanut protein or placebo $(420 \mu \mathrm{L})$ at home on a daily basis for the maintenance period until the Week 44 Unblinding 5g DBPCFC.

After unblinding, subjects on active peanut SLIT continued on maintenance dosing with a $10 \mathrm{~g}$ OFC after approximately 1 year of maintenance therapy. Placebo subjects crossed over to active peanut SLIT and were escalated to a maximum maintenance dose of $3696 \mu \mathrm{g}$ (1120 $\mu \mathrm{L})$. A $5 \mathrm{~g}$ Crossover OFC was performed following 44 weeks of SLIT therapy. For more details about the OFCs, see the Methods section in the Online Repository.

\section{Endpoint titration skin prick testing}

Endpoint titration SPTs were performed with serial ten-fold dilutions of peanut extract at the start of the study and then following approximately 1 year of maintenance peanut SLIT therapy. For details, see the Methods section in the Online Repository.

\section{Immunologic studies}

Basophil activation-Basophil activation was evaluated at baseline and at Weeks 29 and 44 by CD63 up-regulation by flow cytometry. ${ }^{(32)}$

Immunoglobulins-Total IgE was measured by immunoassay, and PN-IgE and peanutspecific IgG4 (PN-IgG4) were measured using the ImmunoCAP 100 (Thermo Fisher Scientific, Waltham, MA) at baseline and at Weeks 29, 44, and 68.

\section{Statistical analysis}

A sample size of 17 per arm was required to provide $90 \%$ power to detect, with a two-sided $5 \%$ level of significance test, a difference between a 5\% desensitization rate for placebotreated versus a 50\% rate for SLIT-treated subjects. The required sample size and analysis used unconditional exact binomial methods (StatXact6). All randomized cases, irrespective of achieved dose, were used in the intent-to-treat analysis of the primary end point with those failing to demonstrate desensitization to peanut consumption at the unblinding time point considered failures in the binary assessment. We increased the sample size to 20 individuals per arm to accommodate potential dropouts or noncompliant cases. With the sample size of 20 per arm, the power is $82 \%$ to detect a difference if the true placebo SLIT desensitization rate is $10 \%$, and the peanut SLIT rate is $50 \%$.

\section{RESULTS}

\section{Study Participants}

Forty subjects ( 8 per institution) were enrolled (20 Peanut SLIT, 20 Placebo), and 68\% were male with a median age of 15.0 years (range 12.2-36.8 years) (Figure 1). Most subjects had a history of other food allergies (78\%), asthma (58\%), or allergic rhinitis (73\%), and less than half had atopic dermatitis (47.5\%). There were no statistical differences in baseline characteristics between treatment groups (Table 1).

\section{Assessment of clinical desensitization}

Week 44 Unblinding 5g DBPCFC—Three subjects (2 Peanut SLIT, 1 Placebo)

withdrew prior to the Week 44 Unblinding OFC; per protocol, these subjects were treated as non-responders. A significantly higher response rate was noted in the active treatment 
group: 14 of $20(70 \%)$ subjects on Peanut SLIT were responders per study criteria versus only 3 of 20 (15\%) receiving placebo ( $<<0.001,95 \%$ CI [22.2\%, 77.6\%]). Among the 14 responders in the Peanut SLIT group, the successfully consumed dose (SCD) was $<500 \mathrm{mg}$ for 8 subjects, $996 \mathrm{mg}$ for 2 subjects, $1996 \mathrm{mg}$ for 1 subject, and $3256 \mathrm{mg}$ for 3 subjects (median $496 \mathrm{mg}$ ) (Figure 2). Among the 3 responders in the Placebo group, 1 successfully consumed $21 \mathrm{mg}$, and the other 2 successfully consumed $5000 \mathrm{mg}$ and passed the challenge (Figure 2). For more details regarding the responders in the Placebo group, please see the Results section in the Online Repository.

The median SCD at Week 44 was significantly higher than the baseline OFC for Peanut SLIT subjects ( $371 \mathrm{mg}$ vs $21 \mathrm{mg}$, respectively; $\mathrm{p}=0.01$ ) but not for Placebo subjects (146 mg vs $71 \mathrm{mg}$, respectively; $\mathrm{p}=0.14$ ). However, the median SCD after 44 weeks of therapy was not significantly different between treatment groups ( $\mathrm{p}=0.16$ ).

Baseline characteristics (age, atopic dermatitis total score, peanut endpoint titer, peanut SPT score, PN-IgE, baseline OFC dose at first symptom, baseline OFC SCD) were examined in Peanut SLIT subjects to identify predictors of response. Only the SCD at the baseline OFC was significantly different between responders compared to non-responders, $3.5 \mathrm{mg}$ versus $246 \mathrm{mg}$, respectively $(\mathrm{p}=0.008)$.

Week 68 10g DBPCFC_All Week 44 responders still being followed were Week 68 responders: no Week 44 non-responders converted to responders at Week 68. For the 15 Peanut SLIT subjects who underwent the Week 68 OFC, the SCD compared to the Week 44 Unblinding OFC declined for 2 subjects, increased for 7 subjects, and remained the same for 6 subjects. Two subjects successfully consumed $10 \mathrm{~g}$ of peanut powder, and 3 others consumed $5 \mathrm{~g}$. The median SCD increased to $996 \mathrm{mg}$, and this was significantly higher than at Week $44(\mathrm{p}=0.05)$ and at Baseline $(\mathrm{p}=0.009)$ (Figure 3).

Week 44 Crossover 5g DBPCFC in initial Placebo group-Seventeen Placebo subjects crossed over to active SLIT at Week 44, escalating to a higher peanut SLIT dose than the initial active group. Among these 17 subjects (Crossover High Dose subjects), 12 completed the Week 44 Crossover OFC. Four discontinued dosing prior to this OFC and were counted as non-responders per protocol; 1 missed this OFC (not evaluable) but continued dosing and was challenged at Week 68. The median SCD at the Week 44 Crossover OFC was significantly higher than at the Baseline OFC (603 mg vs $71 \mathrm{mg}$; $\mathrm{p}=0.02$ ) (Figure 2).

The number of responders among the Crossover High Dose subjects with an evaluable result was $7 / 16(44 \%)$. Among the 7 responders in this group, the SCD was $<500 \mathrm{mg}$ for 4 subjects, $996 \mathrm{mg}$ for 1 subject, $3246 \mathrm{mg}$ for 1 subject, and $4996 \mathrm{mg}$ for 1 subject (median $496 \mathrm{mg}$ ). None of the baseline characteristics, as described above, was significantly different between Crossover High Dose responders and non-responders.

Among the 17 Crossover High Dose subjects who initiated peanut SLIT active dosing, 15 (88\%) were able to attain the maximum maintenance dose of $3696 \mathrm{mg}$. One subject reached a dose of $6.6 \mathrm{mg}$ and discontinued dosing due to adverse symptoms, while the other reached $165 \mathrm{mg}$ and was lost to follow-up.

\section{Immunologic changes}

Immunoglobulins-Baseline PN-IgE levels were not statistically different between Peanut SLIT [median $31.3 \mathrm{kU}_{\mathrm{A}} / \mathrm{L}$ (range $0.4-154.1 \mathrm{kU}_{\mathrm{A}} / \mathrm{L}$ )] and Placebo subjects [median $22.5 \mathrm{kU}_{\mathrm{A}} / \mathrm{L}$ (range, 0.6-207.5 kU $\mathrm{A} / \mathrm{L}$ )] (see Table E2 in the Online Repository). Median PN-IgE levels among Peanut SLIT subjects increased significantly between baseline and 
Week 44 ( $\mathrm{p}=0.035)$, but not between Weeks 44 and 68. $(\mathrm{p}=0.21)$. The change from baseline to Week 44 in PN-IgE levels was not statistically significant ( $\mathrm{p}=0.43$ ) among Placebo subjects or Crossover High Dose subjects ( $\mathrm{p}=0.07$ ) (see Figure E2 in the Online Repository). At Week 44, no statistically significant differences in median PN-IgE levels were detected between Peanut SLIT and Placebo subjects, Peanut SLIT responders and non-responders, or Crossover High Dose and Peanut SLIT subjects.

Baseline PN-IgG4 levels were not significantly different between treatment groups (see Table E2 in the Online Repository). PN-IgG4 levels increased significantly among Peanut SLIT subjects between baseline and Week 44 ( $\mathrm{p}=0.001$ ), but not between Weeks 44 and 68 $(\mathrm{p}=0.42)$. Placebo subjects had no significant change from baseline to Week 44 in median PN-IgG4 levels ( $\mathrm{p}=0.99)$. A statistically significant increase in PN-IgG4 was noted in Crossover High Dose subjects from baseline to Week 44 ( $p<0.001)$. The median change from baseline to Week 44 in PN-IgG4 was significantly different in Peanut SLIT subjects compared to Placebo subjects: 0.3 milligrams of antibody per liter $\left(\mathrm{mg}_{\mathrm{A}} / \mathrm{L}\right)$ vs $0.0 \mathrm{mg}_{\mathrm{A}} / \mathrm{L}$ $(\mathrm{p}<0.001)$ (Figure 4). There were no statistically significant differences in median change from baseline to Week 44 in PN-IgG4 between Peanut SLIT responders and non-responders $(\mathrm{p}=0.33)$ or between Crossover High Dose responders and non-responders $(\mathrm{p}=0.07)$. There was no statistically significant difference in median PN-IgG4 levels at Week 44 or in median change from baseline to Week 44 in PN-IgG4 between Crossover High Dose subjects and Peanut SLIT subjects.

Basophil activation-A repeated measures analysis of percent CD63 positivity (\%CD63+) data from Weeks 29 and 44, with study visit and baseline \%CD63+ as covariates, found the \%CD63+ was significantly lower for Peanut SLIT subjects compared to Placebo subjects for the $10^{-2} \mu \mathrm{g} / \mathrm{mL}$ crude peanut stimulant $(\Delta=-19.2, \mathrm{p}=0.008)$ and the $10^{-3} \mu \mathrm{g} / \mathrm{mL}$ crude peanut stimulant $(\Delta=-11.9, \mathrm{p}=0.049$ (see Figure E3 in the Online Repository), indicating a weak effect on basophil activation. Similar analyses performed between responders and non-responders in the Peanut SLIT group, as well as between Crossover High Dose and Peanut SLIT subjects and between responders and non-responders in the Crossover High Dose group revealed no significant differences.

Peanut SPT and titrated SPT-No difference in baseline median peanut SPT score was detected between treatment groups (Peanut SLIT $13.3 \mathrm{~mm}$, Placebo $12.0 \mathrm{~mm}$; $\mathrm{p}=0.43$ ). Peanut endpoint titration SPT was performed at baseline and at Week 68. There was no statistically significant difference between Peanut SLIT responders and non-responders in baseline peanut SPT score or area under the curve analysis for endpoint titration SPT. However, at Week 68 the median change from baseline for the area under the SPT endpoint titration curve was improved for Week 44 responders (-17.0) vs. non-responders (1.0) $(\mathrm{p}=0.03)$ (see Figure E4 in the Online Repository).

\section{Dosing symptoms, safety, and adverse events}

During the study's first phase (baseline to Week 44 Unblinding challenge), 99.4\% of 6029 placebo doses were symptom-free, whereas only $59.9 \%$ of 5825 Peanut SLIT doses were symptom-free (Table 2). However, upon exclusion of oral/pharyngeal symptoms, $94.7 \%$ of doses were symptom-free in Peanut SLIT subjects. Only 127 of 11,854 total doses (1.1\%) required treatment during the first phase: $125(1.1 \%)$, oral antihistamine only; $1(0.01 \%)$, albuterol only; and $1(0.01 \%)$, epinephrine and oral antihistamine.

In the Crossover High Dose subjects, $66.7 \%$ of 5030 doses from build-up to Week 44 Crossover OFC were symptom-free, increasing to $95.8 \%$ when excluding oral-pharyngeal symptoms. One hundred forty-seven doses $(2.9 \%)$ required treatment: $146(2.9 \%)$, oral 
antihistamine only; and $1(0.02 \%)$, oral antihistamine and albuterol. From the Week 44 Unblinding OFC to Week 68, Peanut SLIT subjects took an additional 2083 doses, of which $64.2 \%$ were symptom-free; $98.9 \%$ were symptom-free when oral-pharyngeal symptoms were excluded. Only one dose $(0.05 \%)$ required treatment with an antihistamine.

A total of 240 adverse events were reported; 234 (97.5\%) were unrelated to study product (e.g., infections [upper respiratory], gastrointestinal disorders [diarrhea], nervous system disorders [headaches]). Thirty-six percent were in the Peanut SLIT subjects, $31 \%$ in the Placebo subjects, and 33\% were in the Crossover High Dose subjects. Eighty-six percent were judged to be mild in severity. One dose-related serious adverse event occurred during the build-up stage in a Peanut SLIT subject. Five minutes after taking the daily dose at home, the subject developed erythema, pruritus, and oral symptoms. Diphenhydramine was administered at home without improvement, and the reaction progressed to include urticaria and coughing. Epinephrine was administered at home, and the subject transported to the study site. After treatment and monitoring, further dosing was discontinued.

Four additional subjects on Peanut SLIT discontinued dosing for the following reasons: noncompliance with therapy; perceived lack of efficacy; opportunity to participate in another food allergy treatment study; and fear of subsequent OFCs. Of the 5 Placebo/ Crossover subjects who discontinued dosing, one each did so for the following reasons: poorly controlled asthma; anxiety with ongoing dosing; pregnancy; lack of desire to continue dosing; and loss to follow-up. (Figure 1).

\section{DISCUSSION}

This is the first multicenter, randomized, placebo-controlled trial of peanut SLIT. The study achieved its primary efficacy end point, demonstrating that treatment with peanut SLIT induces a statistically significant degree of desensitization in a majority of subjects, compared to placebo. Desensitization was also observed in subjects originally randomized to placebo who subsequently crossed over and received treatment with higher dose peanut SLIT.

Although these results are encouraging, none of the subjects treated with lower or lower dose peanut SLIT were able to ingest $5 \mathrm{~g}$ of peanut powder without symptoms during the desensitization challenge, suggesting a modest desensitization effect conferred by 44 weeks of peanut SLIT may not provide clinically relevant protection. Interestingly, a subset of subjects challenged again after 68 weeks of treatment demonstrated incremental, statistically significant increases in the SCD, with three subjects consuming $5 \mathrm{~g}$ of peanut powder without symptoms and two successfully consuming $10 \mathrm{~g}$. These data suggest continued longterm therapy with peanut SLIT might confer reduced reactivity to peanut following further desensitization, allowing for protection from accidental ingestions, which are reactions to less than $100 \mathrm{mg}$ of peanut protein in general.

The clinical effect of peanut SLIT was independent of baseline or quantitative changes in peanut-specific antibody levels. Specifically, clinical improvement was not associated with a reduction in PN-IgE levels at 44 or 68 weeks, consistent with some ${ }^{(33-36)}$ but not all ${ }^{(20 ; 37-39)}$ studies of allergen immunotherapy. Active peanut SLIT but not placebo increased the PN-IgG4 levels, but there was no difference between responders and nonresponders. Although statistically significant inhibition of basophil reactivity in vitro was detected in Peanut SLIT subjects compared to Placebo subjects, these finding were not significant when comparing Peanut SLIT or Crossover High Dose responders and nonresponders. Peanut SLIT responders compared to non-responders, however, experienced significant suppression in the peanut SPT size by week 68 . These data suggest that the 
desensitization observed in our study may have been mediated by reduced mast cell reactivity, but further mechanistic studies are warranted with long-term therapy.

Other studies have demonstrated that blocking IgG antibody, ${ }^{(40)}$ regulatory T cells, ${ }^{(40-42)}$ and salivary $\operatorname{Ig} \mathrm{A}^{(40 ; 43)}$ are associated with therapeutic effects of SLIT with aeroallergens and food allergens, but we did not examine these parameters specifically in this analysis. We were unable to identify subject characteristics that would predict therapeutic response to peanut SLIT; the only factor that was significantly different between responders and nonresponders was the SCD at the baseline OFC in subjects during the first phase. However, since a successful response was defined as a 10-fold increase from the baseline SCD, subjects with a lower dose at baseline had to consume a lesser absolute amount of peanut powder at Week 44 to be considered a responder. Therefore, this finding may reflect our definition of a responder rather than being a true predictor of response to therapy. Although limited by the small sample size, this dose effect was not significant in the Crossover High Dose cohort.

In Peanut SLIT subjects, the majority of dose-related symptoms involved only the oropharyngeal mucosa. Subjects in the initial Peanut SLIT and Crossover High Dose arms reported symptoms that required treatment following 1 and $3 \%$ of doses, respectively, generally including only an oral antihistamine. These findings suggest an overall favorable safety profile of peanut SLIT. However, one subject experienced Grade 1 anaphylaxis ${ }^{(44)}$ within 5 minutes following a home dose of $66 \mu \mathrm{g}$ after safely consuming the same build-up dose without symptoms in the clinical research unit. Treatment included self-administration of diphenhydramine and epinephrine with urgent evaluation by study staff. The subject recovered without sequelae, but further dosing was discontinued. Similar sentinel events have been reported in other SLIT protocols. ${ }^{(45 ; 46)}$ Ten subjects were unable to complete the protocol, including 3 during the initial build-up period, primarily for reasons including poor compliance/loss of motivation, anxiety, perceived lack of efficacy, and poorly controlled asthma. Before peanut SLIT could be considered for use in the general population, further study is necessary to better understand the safety profile and develop methods to increase adherence.

Although several studies of OIT for food allergy have been published, ${ }^{(19 ; 20)}$ few rigorous trials have investigated SLIT. ${ }^{(29 ; 30)}$ In an ongoing, single-center placebo controlled clinical trial, Kim et al evaluated peanut SLIT in pediatric subjects. ${ }^{(25)}$ Similar to the current study, they utilized a 1:1 randomization scheme, assigned a $2 \mathrm{mg}$ per day maintenance dose, and performed a per-protocol interim analysis of desensitization as the primary efficacy end point, measured by a $2.5 \mathrm{~g}$ peanut protein $(5 \mathrm{~g}$ peanut powder) DBPCFC after 52 weeks of therapy. Interestingly, both studies (1) met their primary statistical end point; (2) showed significant variation in the clinical desensitization effect size; (3) demonstrated evidence of skin test (i.e., mast cell) suppression; and (4) observed increases in allergen-specific IgG4 levels among actively treated subjects. Although formal statistical comparisons are not possible, Kim et al reported a several-fold higher median tolerated dose and increased suppression of peanut-induced basophil activation. It is possible that by enrolling pediatric subjects aged 1-11 years and treating with $2 \mathrm{mg}$ per day, Kim et al may have capitalized on factors, including young age and less established immune deviation, that enabled a larger therapeutic effect. Alternatively, or in combination, the differences may be due to the overestimation of effect size that may occur in single-center interventional trials, as compared to multicenter trials. ${ }^{(47 ; 4)}$ Although promising, given the relatively modest clinical and immunologic effect observed in peanut-allergic subjects treated with SLIT, more study is needed to determine if this approach is clinically useful as a potential treatment for peanut allergy. 
There are limitations to our study. First, our definition of success may not accurately predict therapeutic response to peanut SLIT, as there were subjects who had large increases in SCD from baseline (i.e. $500 \mathrm{mg}$ to $>2 \mathrm{~g}$ ). However, these subjects were labeled as non-responders by definition since they failed to consume a 10-fold increase in SCD from baseline because they were starting from a relatively higher baseline SCD. Although these subjects were nonresponders by study definition, they may have experienced some clinical benefit from peanut SLIT in protection from accidental exposures given the large increases in SCD from baseline. Second, subjects receiving active SLIT reported symptoms, primarily oropharyngeal pruritus, approximately $40 \%$ of the time whereas almost all placebo doses were symptom-free, a finding that could have potentially affected the blinding of the study. This concern is mitigated by measuring the primary outcome variable with a DBPCFC, the results of which are less influenced by knowledge of treatment assignment. Third, although done for safety reasons, we did not enroll peanut-allergic patients who had a history of lifethreatening reactions. It is possible these patients may have a different therapeutic response, which is important to consider because these subjects may be more likely to seek treatment if an effective therapy becomes available. Therefore, it will be important in future clinical trials with peanut SLIT to include all severities of peanut-allergic subjects to potentially eliminate the bias seen in this study by not including those with severe anaphylaxis. Fourth, there was a high dropout rate in this trial, primarily due to logistical or personal reasons. Fifth, as in other SLIT studies ${ }^{(25 ; 28 ; 30)}$ due to volume and potency constraints of available materials, dosing options for SLIT are limited. As a result, the doses given in SLIT are minuscule $(\mathrm{mg})$ when compared to the much larger gram doses given in OIT. Finally, our results reflect only desensitization, and offer no insight into long-term tolerance or incorporation of the food into the normal diet.

Interestingly, two subjects in the placebo group developed spontaneous tolerance to peanut during the course of the trial. Data from observational natural history studies suggest spontaneous tolerance occurs in up to $20 \%$ of children with peanut allergy. ${ }^{(49-51)}$ These and other studies have shown that tolerance development generally can be expected only in young children and those with low IgE levels. However, it remains possible that such observational studies may underestimate the rate of spontaneous tolerance development, especially in adolescents and adults. ${ }^{(52)}$ This must be kept in mind when interpreting the results of clinical trials lacking an adequate control group.

In summary, we report the initial results of the first multicenter, randomized clinical trial of peanut SLIT. This potential therapy was relatively safe, and 44 weeks of treatment was sufficient to produce clinical desensitization in some subjects. The immunomodulatory effects of peanut SLIT studied here were modest during the first year of the study.

Additional clinical benefits are noted when higher doses and longer treatment courses were used. Further investigation of SLIT as a treatment for food allergy is warranted.

\section{Supplementary Material}

Refer to Web version on PubMed Central for supplementary material.

\section{Acknowledgments}

Additional Site Investigators: FM Atkins, DYM Leung, TT Perry.

Coordinators and support: D Brown, J Gau, K Mudd, S Driggers, P Steele, J Kamilaris, S Carlisle, A Hiegel, J Straw, P Mayfield, L Christie, M Groetch, J Slinkard, and S Leung.

We thank J Poyser, for managing the project for CoFAR (NIAID). We thank the families who kindly participated. We thank the staff of the clinical research units at each institution and the Statistical and Clinical Coordinating 
Center, without whose participation the study could not have been done. We thank Greer (Lenoir, NC) and Thermo Fisher Scientific (Waltham, MA) for supplying reagents.

Sources of support: NIH-NIAID U19AI066738 and U01AI066560. The project was also supported by Grant Numbers UL1 RR025780 from the National Center for Research Resources (NCRR)/National Institutes of Health (NIH) and UL1 TR000154 from the NIH/National Center for Advancing Translational Sciences (National Jewish); Grant Numbers UL1 TR000067 (Mount Sinai), UL1 TR000039 (Arkansas), UL 1 RR024128 (North Carolina) and UL1 RR 025005 (Johns Hopkins) from the NCRR. Its contents are solely the responsibility of the authors and do not necessarily represent the official view of the NCRR or NIH.

\section{Abbreviations}

$\begin{array}{ll}\text { OIT } & \text { oral immunotherapy } \\ \text { SLIT } & \text { sublingual immunotherapy } \\ \text { OFC } & \text { oral food challenge } \\ \text { SPT } & \text { skin prick test } \\ \text { DSMB } & \text { Data Safety Monitoring Board } \\ \text { PN-IgE } & \text { peanut-specific IgE } \\ \text { kU } \mathbf{A} / \mathbf{L} & \text { kilounits of antibody per liter } \\ \text { DBPCFC } & \text { double-blind, placebo-controlled food challenge } \\ \text { PN-IgG4 } & \text { peanut-specific IgG4 } \\ \text { SCD } & \text { successfully consumed dose } \\ \text { mg } \mathbf{A} / \mathbf{L} & \text { milligrams of antibody per liter }\end{array}$

\section{REFERENCES}

1. Sicherer SH, Munoz-Furlong A, Godbold JH, Sampson HA. US prevalence of self reported peanut, tree nut, and sesame allergy: 11-year follow-up. J Allergy Clin Immunol. 2010; 125:1322-1326. [PubMed: 20462634]

2. Bock SA, Munoz-Furlong A, Sampson HA. Fatalities due to anaphylactic reactions to foods. J Allergy Clin Immunol. 2001; 107:191-193. [PubMed: 11150011]

3. Bock SA, Munoz-Furlong A, Sampson HA. Further fatalities caused by anaphylactic reactions to food: 2001-2006. J Allergy Clin Immunol. 2007; 119:1016-1018. [PubMed: 17306354]

4. Ford LS, Taylor SL, Pacenza R, Niemann LM, Lambrecht DM, Sicherer SH. Food allergen advisory labeling and product contamination with egg, milk, and peanut. J Allergy Clin Immunol. 2010; 126:384-385. [PubMed: 20621349]

5. Sicherer SH, Burks AW, Sampson HA. Clinical Features of Acute Allergic Reactions to Peanut and Tree Nuts in Children. Pediatrics. 1998; 102:e6. [PubMed: 9651458]

6. Fleischer DM, Perry TT, Atkins D, Wood RA, Burks AW, Jones SM et al. Allergic Reactions to Foods in Preschool-Aged Children in a Prospective Observational Food Allergy Study. Pediatrics. 2012; 130:e25-e32. [PubMed: 22732173]

7. Clark S, Bock SA, Gaeta TJ, Brenner BE, Cydulka RK, Camargo CA. Multicenter study of emergency department visits for food allergies. J Allergy Clin Immunol. 2004; 113:347-352. [PubMed: 14767453]

8. Altschul AS, Scherrer DL, Munoz-Furlong A, Sicherer SH. Manufacturing and labeling issues for commercial products: relevance to food allergy. J Allergy Clin Immunol. 2001; 108:468. [PubMed: 11544472]

9. Joshi P, Mofidi S, Sicherer SH. Interpretation of commercial food ingredient labels by parents of food-allergic children. J Allergy Clin Immunol. 2002; 109:1019-1021. [PubMed: 12063534]

10. Sicherer SH, Noone SA, Munoz-Furlong A. The impact of childhood food allergy on quality of life. Ann Allergy Asthma Immunol. 2001; 87:461-464. [PubMed: 11770692] 
11. Cohen BL, Noone S, Munoz-Furlong A, Sicherer SH. Development of a questionnaire to measure quality of life in families with a child with food allergy. J Allergy Clin Immunol. 2004; 114:11591163. [PubMed: 15536425]

12. Bollinger ME, Dahlquist LM, Mudd K, Sonntag C, Dillinger L, McKenna K. The impact of food allergy on the daily activities of children and their families. Ann Allergy Asthma Immunol. 2006; 96:415-421. [PubMed: 16597075]

13. King RM, Knibb RC, Hourihane JO'B. Impact of Peanut Allergy on Quality of Life, Stress and Anxiety in the Family. Allergy. 2009; 64:461-468. [PubMed: 19076542]

14. DunnGalvin A, de BlokFlokstra BMJ, Burks AW, Dubois EJ, Hourihane JO'B. Food allergy QoL questionnaire for children aged 0-12 years: content, construct, and cross-cultural validity. Clin Exp Allergy. 2008; 38:977-988. [PubMed: 18435800]

15. Guest JF, Nagy E. Modelling the resource implications and budget impact of managing cow milk allergy in Australia. Curr Med Res Opin. 2009; 25:339-349. [PubMed: 19192978]

16. Sladkevicius E, Nagy E, Lack G, Guest JF. Resource implications and budget impact of managing cow milk allergy in the UK. J Med Econ. 2010; 13:119-128. [PubMed: 20092426]

17. Patel DA, Holdford DA, Edwards E, Carroll NV. Estimating the economic burden of food-induced allergic reactions and anaphylaxis in the United States. J Allergy Clin Immunol. 2011; 128:110 115. [PubMed: 21489610]

18. Nelson HS, Lahr J, Rule R, Bock SA, Leung DY. Treatment of anaphylactic sensitivity to peanuts by immunotherapy with injections of aqueous peanut extract. J Allergy Clin Immun. 1997; 99:744-751. [PubMed: 9215240]

19. Nowak-Wegrzyn A, Sampson HA. Future therapies for food allergies. J Allergy Clin Immunol. 2011; 127:558-573. [PubMed: 21277625]

20. Burks AW, Jones SM, Wood RA, Fleischer DM, Sicherer SH, Lindblad RW, et al. Oral Immunotherapy for Treatment of Egg Allergy in Children. New Engl J Med. 2012; 367:233-243. [PubMed: 22808958]

21. Sheikh A, Nurmatov U, Venderbosch I, Bischoff E. Oral immunotherapy for the treatment of peanut allergy: systematic review of six case series studies. Prim Care Resp J. 2012; 21:41-49.

22. Wilson DR, Torres Lima M, Durham SR. Sublingual immunotherapy for allergic rhinitis: systematic review and meta-analysis. Allergy. 2005; 60:4-12. [PubMed: 15575924]

23. Cox LS, Linnemann DseL, Nolte H, Weldon D, Finegold I, Nelson HS. Sublingual immunotherapy: A comprehensive review. J Allergy Clin Immunol. 2006; 117:1021-1035. [PubMed: 16675328]

24. Rodriguez-Perez N, Ambriz-Moreno MdJ, Canonica GW, Penagos M. Frequency of acute systemic reactions in patients with allergic rhinitis and asthma treated with sublingual immunotherapy. Ann Allergy Asthma Immunol. 2008; 101:304-310. [PubMed: 18814454]

25. Kim EH, Bird JA, Kulis M, Laubach S, Pons L, Shreffler W, et al. Sublingual immunotherapy for peanut allergy: Clinical and immunologic evidence of desensitization. J Allergy Clin Immunol. 2011; 127:640-646. [PubMed: 21281959]

26. Kerzl R, Simonowa A, Ring J, Ollert M, Mempel M. Life-threatening anaphylaxis to kiwi fruit: Protective sublingual allergen immunotherapy effect persists even after discontinuation. J Allergy Clin Immunol. 2007; 119:507-508. [PubMed: 17125821]

27. Mempel M, Rakoski J, Ring J, Ollert M. Severe anaphylaxis to kiwi fruit: Immunologic changes related to successful sublingual allergen immunotherapy. J Allergy Clin Immunol. 2003; 111:1406-1409. [PubMed: 12789247]

28. Enrique E, Pineda F, Malek T, Bartra J, Basagana M, Tella R, et al. Sublingual immunotherapy for hazelnut food allergy: A randomized, double-blind, placebo controlled study with a standardized hazelnut extract. J Allergy Clin Immunol. 2005; 116:1073-1079. [PubMed: 16275379]

29. Enrique E, Malek T, Pineda F, Palacios R, Bartra J, Tella R, et al. Sublingual immunotherapy for hazelnut food allergy: a follow-up study. Ann Allergy Asthma Immunol. 2008; 100:283-284. [PubMed: 18429351]

30. Keet CA, Frischmeyer-Guerrerio PA, Thyagarajan A, Schroeder JT, Hamilton RG, Boden S, et al. The safety and efficacy of sublingual and oral immunotherapy for milk allergy. J Allergy Clin Immunol. 2012; 129:448-455. [PubMed: 22130425] 
31. Fernandez-Rivas M, Garrido Fernandez S, Nadal JA, Alonso Diaz de Durana MD, Garcia BE, Gonzalez-Mancebo E, et al. Randomized double-blind, placebo-controlled trial of sublingual immunotherapy with a Pru p 3 quantified peach extract. Allergy. 2009; 64:876-883. [PubMed: 19183164]

32. Wanich N, Nowak-Wegrzyn A, Sampson HA, Shreffler WG. Allergen-specific basophil suppression associated with clinical tolerance in patients with milk allergy. J Allergy Clin Immunol. 2009; 123:789-794. [PubMed: 19348919]

33. Morriset M, Moneret-Vautrin DA, Guenard L, Cuny JM, Frentz P, Hatahet R, et al. Oral desensitization in children with milk and egg allergies obtains recovery in a significant proportion of cases. A randomized study in 60 children with cow's milk allergy and 90 children with egg allergy. Eur Ann Allergy Clin Immunol. 2007; 39:12-19.

34. Staden U, Rolinck-Werninghaus C, Brewe F, Wahn U, Niggemann B, Beyer K. Specific oral tolerance induction in food allergy in children: efficacy and clinical patterns of reaction. Allergy. 2007; 62:1261-1269. [PubMed: 17919140]

35. Longo G, Barbi E, Berti I, Meneghetti R, Pittalis A, Ronfani L, et al. Specific oral tolerance induction in children with very severe cow's milk-induced reactions. J Allergy Clin Immunol. 2008; 121:343-347. [PubMed: 18158176]

36. Jones SM, Pons L, Roberts JL, Scurlock AM, Perry TT, Kulis M, et al. Clinical efficacy and immune regulation with peanut oral immunotherapy. J Allergy Clin Immunol. 2009; 124:292-300. [PubMed: 19577283]

37. Meglio P, Bartone E, Plantamura M, Arabito E, Giampietro PG. A protocol for oral desensitization in children with IgE-mediated cow's milk allergy. Allergy. 2004; 59:980-987. [PubMed: 15291907]

38. Skripak JM, Nash SD, Rowley H, Brereton NH, Oh S, Hamilton RG, et al. A randomized, doubleblind, placebo-controlled study of milk oral immunotherapy for cow's milk allergy. J Allergy Clin Immunol. 2008; 122:1154-1160. [PubMed: 18951617]

39. Blumchen K, Ulbricht H, Staden U, Dobberstein K, Beschorner J, de Oliveira LCL, et al. Oral peanut immunotherapy in children with peanut anaphylaxis. J Allergy Clin Immunol. $2010 \mathrm{Jul}$. 126:83-91.e.1. [PubMed: 20542324]

40. Scadding GW, Shamji MH, Jacobson MR, Lee DI, Wilson D, Lima MT et al. Sublingual grass pollen immunotherapy is associated with increases in sublingual Foxp3-expressing cells and elevated allergen-specific immunoglobulin G4, immunoglobulin A and serum inhibitory activity for immunoglobulin E-facilitated allergen binding to B cells. Clin Exp Allergy. 2010; 40:598-606. [PubMed: 20184605]

41. O'Hehir RE, Gardner LM, de Leon MP, Hales BJ, Biondo M, Douglass JA, et al. House Dust Mite Sublingual Immunotherapy. Am J Resp Crit Care Med. 2009; 180:936-947. [PubMed: 19696440]

42. Bohle B, Kinaciyan T, Gerstmayr M, Radakovics A, Jahn-Schmid B, Ebner C. Sublingual immunotherapy induces IL-10-producing T regulatory cells, allergen-specific T-cell tolerance, and immune deviation. J Allergy Clin Immunol. 2007; 120:707-713. [PubMed: 17681368]

43. Kulis M, Saba K, Kim EH, Bird JA, Kamilaris N, Vickery BP, et al. Increased peanut specific IgA levels in saliva correlate with food challenge outcomes after peanut sublingual immunotherapy. J Allergy Clin Immunol. 2012; 129:1159-1162. [PubMed: 22236732]

44. Sampson HA, Munoz-Furlong A, Campbell RL, Adkinson J, Bock SA, Branum A, et al. Second symposium on the definition and management of anaphylaxis: Summary report: Second National Institute of Allergy and Infectious Disease/Food Allergy and Anaphylaxis Network symposium. J Allergy Clin Immunol. 2006; 117:391-397. [PubMed: 16461139]

45. De Groot H, Bijl A. Anaphylactic reaction after the first dose of sublingual immunotherapy with grass pollen tablet. Allergy. 2009; 64:963-964. [PubMed: 19222420]

46. Calderon MA, Simons FER, Malling HJ, Lockey RF, Moingeon P, Demoly P. Sublingual allergen immunotherapy: mode of action and its relationship with the safety profile. Allergy. 2012; 67:302311. [PubMed: 22150126]

47. Bafeta A, Dechartres A, Trinquart L, Yavchitz A, Boutron I, Ravaud P. Impact of single centre status on estimates of intervention effects in trials with continuous outcomes: metaepidemiological study. BMJ. 2012; 344:e813. [PubMed: 22334559] 
48. Dechartres A, Boutron I, Trinquart L, Charles P, Ravaud P. Single-Center Trials Show Larger Treatment Effects Than Multicenter Trials: Evidence From a Meta-epidemiologic Study. Ann Int Med. 2011; 155:39-51. [PubMed: 21727292]

49. Neuman-Sunshine DL, Eckman JA, Keet CA, Matsui EC, Peng RD, Lenehan PJ, et al. The natural history of persistent peanut allergy. Ann Allergy Asthma Immunol. 2012; 108:326-331. [PubMed: 22541403]

50. Fleischer DM, Conover-Walker MK, Christie L, Burks AW, Wood RA. The natural progression of peanut allergy: Resolution and the possibility of recurrence. J Allergy Clin Immunol. 2003; 112:183-189. [PubMed: 12847497]

51. Skolnick HS, Conover-Walker MK, Koerner CB, Sampson HA, Burks W, Wood RA. The natural history of peanut allergy. J Allergy Clin Immunol. 2001; 107:367-374. [PubMed: 11174206]

52. Savage JH, Limb SL, Brereton NH, Wood RA. The natural history of peanut allergy: Extending our knowledge beyond childhood. J Allergy Clin Immunol. 2007; 120:717-719. [PubMed: 17765758] 


\section{Clinical implications}

Peanut sublingual immunotherapy safely induces some level of clinical desensitization in a majority of treated subjects when compared to placebo. Further study to determine whether it is a therapeutic option is warranted. 


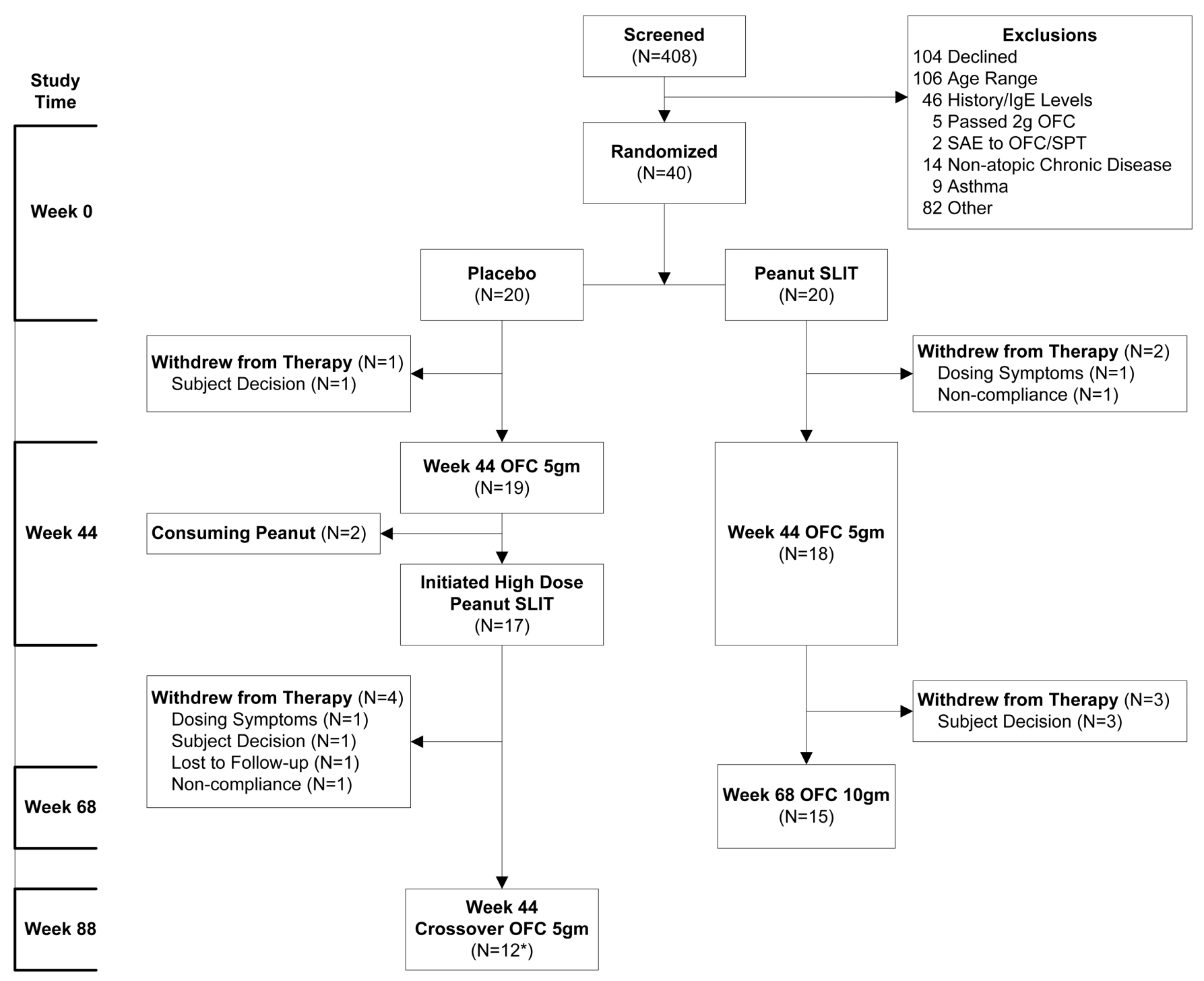

Figure 1. Enrollment and Disposition of Subjects

The 40 subjects who passed screening were randomized onto placebo or peanut SLIT. After the Week 44 oral food challenge, the study was unblinded. Subjects in the original Peanut SLIT group continued on maintenance peanut SLIT therapy and received a Week 68 oral food challenge. Original placebo recipients were offered a higher dose peanut SLIT from week 44 to week 88 , and then an oral food challenge. 


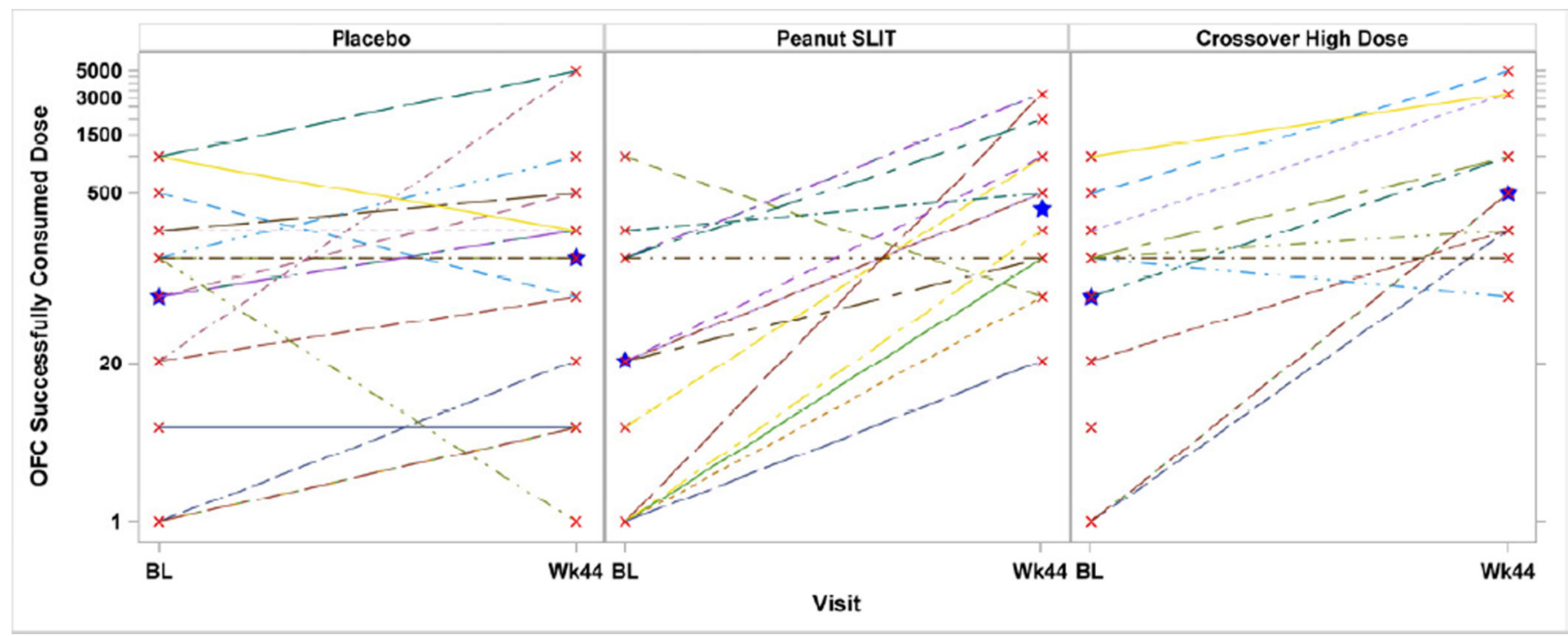

Figure 2. Oral Food Challenge Successfully Consumed Dose by Treatment Group

Oral food challenge doses successfully consumed were compared to initial $2 \mathrm{~g}$ baseline successfully consumed doses after 44 weeks of therapy from study entry for randomized, initially treated group; and after 44 weeks of therapy from crossover initiation for Crossover High Dose group. The median oral food challenge successfully consumed dose at Week 44 was significantly higher than at baseline oral food challenge for Peanut SLIT subjects (21mg vs $371 \mathrm{mg}$; $\mathrm{p}=0.01$ ) but was not for Placebo subjects ( $71 \mathrm{mg}$ vs $146 \mathrm{mg} ; \mathrm{p}=0.14)$. Star identifies the median. 


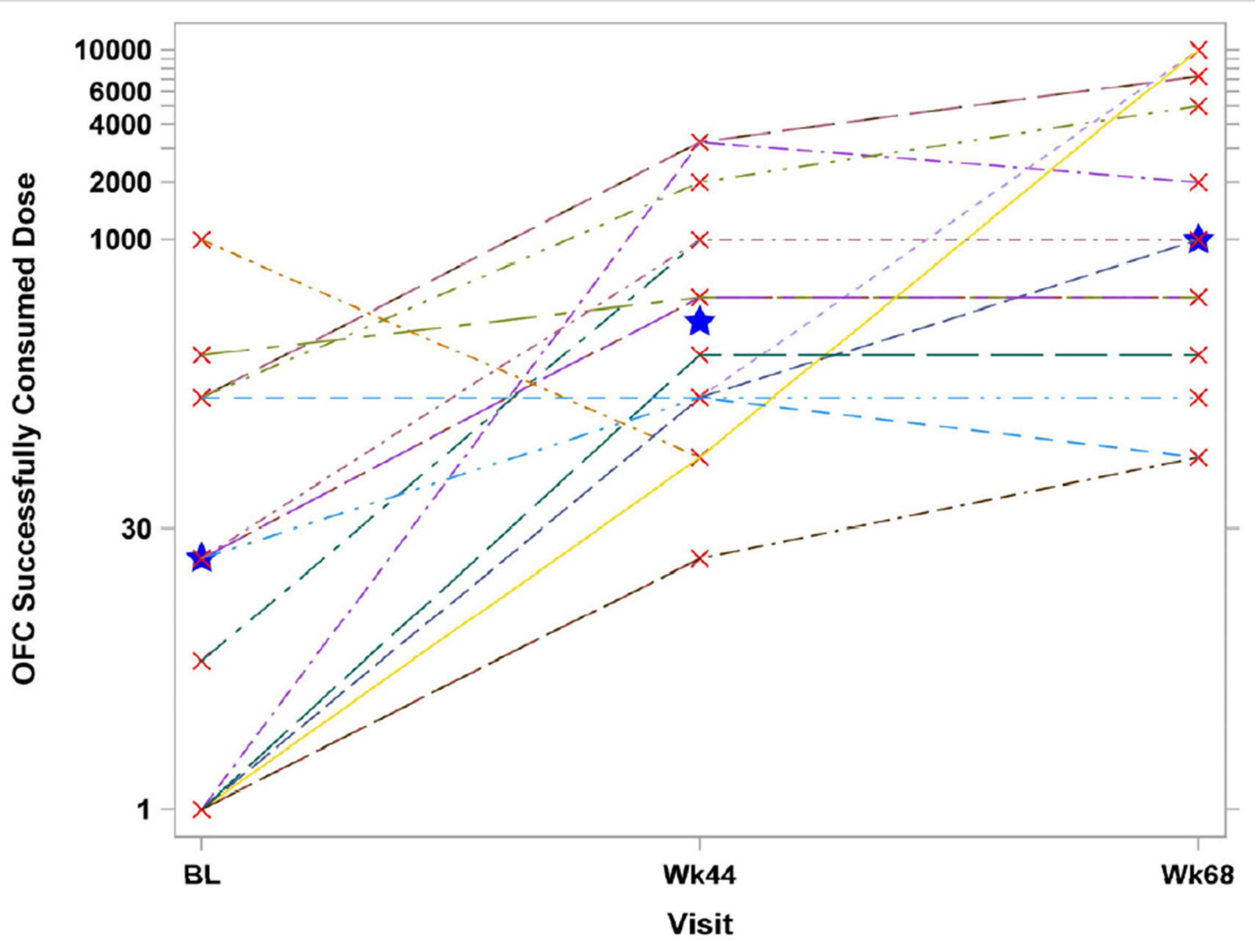

Figure 3. Oral Food Challenge Successfully Consumed Dose for Peanut SLIT Subjects Who Have Week 68 Oral Food Challenge

The oral food challenge successfully consumed doses of subjects are shown by the oral food challenge doses successfully consumed at Baseline, Week 44 and Week 68 for Peanut SLIT subjects. At Week 68, the median dose successfully consumed increased to $996 \mathrm{mg}$, and this was significantly higher than at Week $44(\mathrm{p}=0.05)$ and at Baseline $(\mathrm{p}=0.009)$. Star identifies the median. 


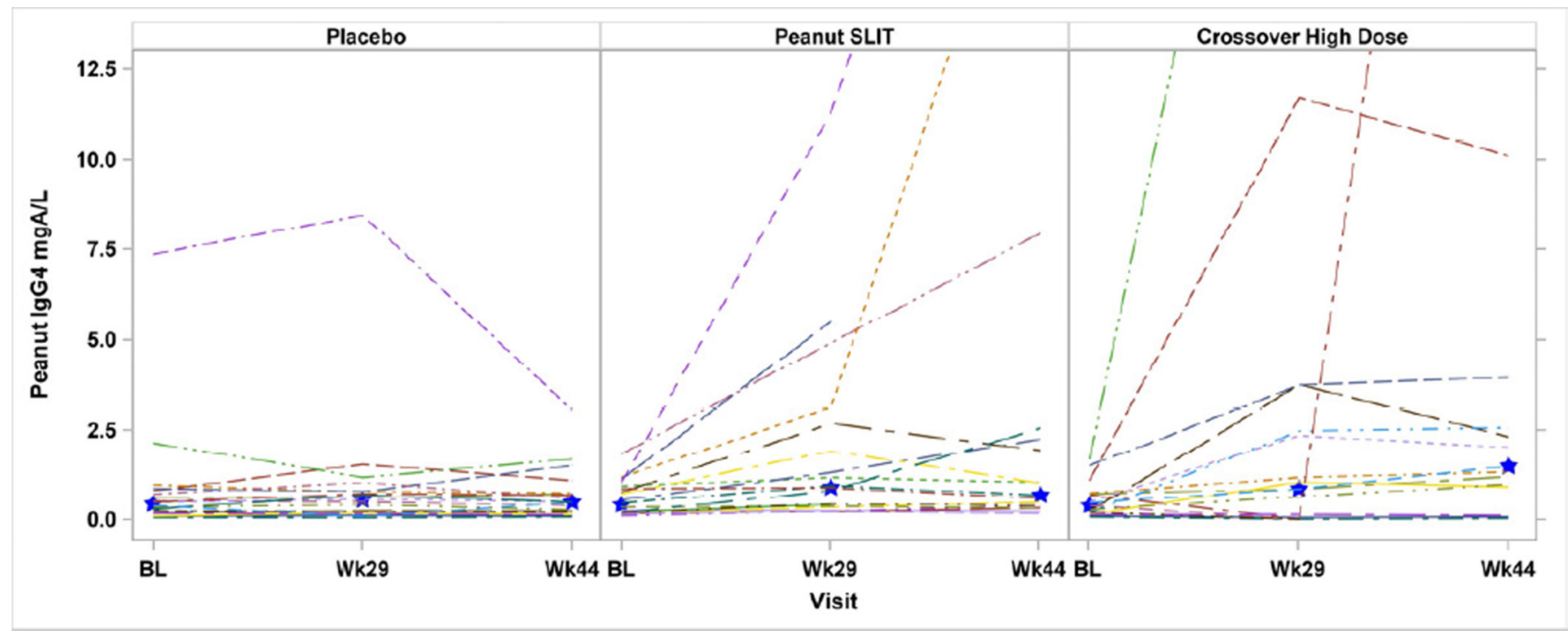

Figure 4. Change in Peanut-Specific IgG4 During SLIT

Levels were compared after 44 weeks of therapy from study entry for the randomized, initially treated group; and after 44 weeks of therapy from crossover initiation for the Crossover High Dose group. Median increase in PN-IgG4 from baseline to Week 44 was statistically significantly higher Crossover High Dose subjects $(\mathrm{p}<0.001)$ and in Peanut SLIT compared to placebo $\left(0.3 \mathrm{mg}_{\mathrm{A}} / \mathrm{L}\right.$ vs $\left.0.0 \mathrm{mg}_{\mathrm{A}} / \mathrm{L} ; \mathrm{p}<0.001\right)$. Star identifies the median. 
Table 1

Baseline Characteristics

\begin{tabular}{|c|c|c|}
\hline & \multicolumn{2}{|c|}{ Treatment } \\
\hline & $\begin{array}{c}\text { Placebo } \\
(\mathbf{N}=20)\end{array}$ & $\underset{(\mathbf{N}=\mathbf{2 0})}{\text { Peanut SLIT }}$ \\
\hline & $\%$ & $\%$ \\
\hline Male Gender & 70.0 & 65.0 \\
\hline Additional Food Allergy & 70.0 & 85.0 \\
\hline Physician Diagnosis Asthma & 60.0 & 55.0 \\
\hline \multirow[t]{2}{*}{ Allergic Rhinitis } & 75.0 & 70.0 \\
\hline & $\begin{array}{c}\text { Median } \\
{[Q 1, Q 3]}\end{array}$ & $\begin{array}{c}\text { Median } \\
{[Q 1, \text { Q3] }}\end{array}$ \\
\hline Age (years) & $\begin{array}{c}16.0 \\
{[13.5,18.5]}\end{array}$ & $\begin{array}{c}14.0 \\
{[13.0,18.0]}\end{array}$ \\
\hline Baseline Atopic Dermatitis Total Score & $\begin{array}{c}0.0 \\
{[0.0,1.5]}\end{array}$ & $\begin{array}{c}0.0 \\
{[0.0,3.0]}\end{array}$ \\
\hline Baseline Peanut Endpoint Titer & $\begin{array}{c}2000 \\
{[200,20000]}\end{array}$ & $\begin{array}{c}2000 \\
{[1100,11000]}\end{array}$ \\
\hline Baseline Skin Prick Test Peanut Score (mm) & $\begin{array}{c}12.0 \\
{[9.0,16.5]}\end{array}$ & $\begin{array}{c}13.3 \\
{[9.5,17.5]}\end{array}$ \\
\hline Baseline Peanut IgE $\left(\mathrm{kU}_{\mathrm{A}} / \mathrm{L}\right)$ & $\begin{array}{c}22.5 \\
{[3.3,77.7]}\end{array}$ & $\begin{array}{c}31.3 \\
{[3.2,42.4]}\end{array}$ \\
\hline Baseline OFC Dose at First Symptom (mg) & $\begin{array}{c}6.0 \\
{[3.5,71.0]}\end{array}$ & $\begin{array}{c}6.0 \\
{[1.0,46.0]}\end{array}$ \\
\hline Baseline OFC Successfully Consumed Dose (mg) & $\begin{array}{c}71.0 \\
{[3.5,196.0]}\end{array}$ & $\begin{array}{c}21.0 \\
{[1.0,146.0]}\end{array}$ \\
\hline
\end{tabular}




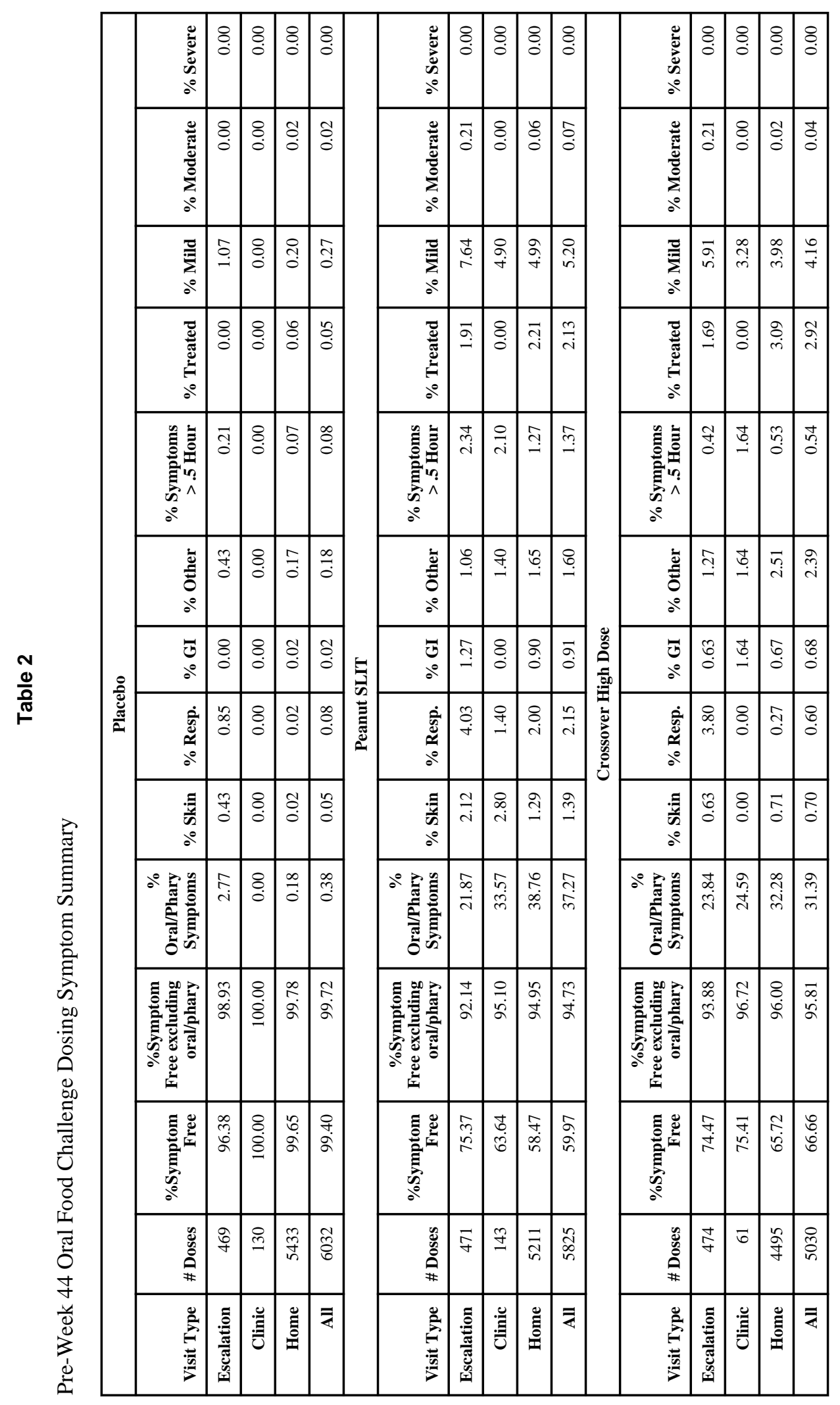

